\title{
Analysis of Verdicchio harvest data in Matelica appellation area during the 1989-2016 time series
}

\author{
Luca Pallotti $^{1 *}$, Roberto Potentini ${ }^{2}$, Tiziano Casturà ${ }^{2}$, Vania Lanari $^{1}$, Tania Lattanzi $^{1}$, Edoardo Dottori ${ }^{1}$ and Oriana \\ Silvestroni ${ }^{1}$ \\ ${ }^{1}$ Dipartimento di Scienze Agrarie, Alimentari e Ambientali, Università Politecnica delle Marche, 60131, Ancona, Italy \\ ${ }^{2}$ Azienda vitivinicola Cantine Belisario s.a.c., 62024, Matelica, Italy
}

\begin{abstract}
The knowledge of the climatological trend of an area and its influences on grapevine growth is a helpful tool for the prediction of the ripening process: climate change effects on viticulture can be thus studied. In a first step, the climate of the Matelica area, central Italy, was characterized, then Verdicchio grapevines harvest data and its connection with seasonal trends have been evaluated for a period of almost thirty years. This study allowed us to find a connection between mean harvest date and heat summation from March to June, while berry sugar accumulation proved to be more influenced by the heat summation of June-August period. These relations can represent a useful tool for wineries and vine-growers to monitor the ripening process and prediction of harvest, helping in their management.
\end{abstract}

\section{Introduction}

Nowadays, one of the biggest challenges viticulture must face is climate change. 2018 IPCC (International Panel on Climate Change) estimated an increase of $+1^{\circ} \mathrm{C}$ in global mean temperature since pre-industrial era and it foresees that it might reach $+1.5{ }^{\circ} \mathrm{C}$ between 2030 and 2052 if the actual trend doesn't change, with disastrous impacts on natural and anthropic systems and their related services [1].

In the Marche region, on the eastern side of central Italy, the effects of climate change have been described by a study carried out by the Protezione Civile della Regione Marche. From the analysis of a dataset collected from 24 meteorological stations throughout the region for the period 1950-2000 it has been shown a general rise in temperatures [2]. More specifically, the paper reported a growth of annual minimum temperature between $+0.8^{\circ} \mathrm{C}$ and $+1.7^{\circ} \mathrm{C}$ every fifty years for all 24 stations under analysis and an increase in annual maximum temperature between $+0.5{ }^{\circ} \mathrm{C}$ and $+1.3{ }^{\circ} \mathrm{C}$ every fifty years in all the stations but one. Considering seasonal trends, minimum temperatures showed a rise of $+1.1{ }^{\circ} \mathrm{C}$ in spring, of $+1.4{ }^{\circ} \mathrm{C}$ in summer, of $+1.0^{\circ} \mathrm{C}$ in autumn and of $+1.3{ }^{\circ} \mathrm{C}$ in winter, while maximum temperatures displayed this growth only for summer and winter, with mean values of $+1.1{ }^{\circ} \mathrm{C}$ and $+1.2{ }^{\circ} \mathrm{C}$, respectively.

Nowadays, in viticulture there is a large use of bioclimatic indexes to estimate the influence of temperature on growth and ripening processes and on the suitability of some areas to develop specific sensory characteristics required for high-quality wines. In addition to this, the increasing interest towards global warming, and its related issues, has meant that there are lots of information from various studies on this topic.
Montepulciano grapes grown in the Abruzzo region, in central Italy, in the years between 1974 to 2013 showed an early harvest date strictly linked with thermal availability registered from March to June [3], while thermal availability during summer, especially from July to September, seems to affect mostly sugar accumulation [4].

Studies carried out in nine vine-growing areas of Spain, France, Germany, Italy, and Slovakia reveal a strong connection between temperatures from April to October and phenological evolution [5]. The elaboration of a dataset describing the phenology of an ampelographic collection located in northern Italy showed in the 1964-2009 time series an advance of 16 and 19 days for the flowering and harvest dates respectively [6]. Similarly, observations from three different areas of the Abruzzo region (central Italy) highlighted that climate change has led to a significative reduction of the period budburst-harvest, mostly through anticipation of harvest date [3].

After early flowering, grape ripening now occurs in a period with higher temperatures when compared to the past. Thus, grapes showed a faster sugar accumulation and consequently a higher alcoholic concentration in wine. This generates problems during the malolactic fermentation, higher volatile acidity, and more unbalanced wines (particularly for red ones); in addition to that, more alcoholic wines are subject to higher taxation in some countries, making their market more tough to deal with [7]. Another consequence of this faster grape sugar accumulation is that technological maturity is obtained before phenological maturity which is in contrast with current market tendency to prefer more full-bodied wines [8]. Moreover, other studies highlight how berry earlier ripening, when air temperatures are usually higher, is conducting $s$ to musts

\footnotetext{
* Corresponding author: 1.pallotti@pm.univpm.it
} 
with lower acidity, higher $\mathrm{pH}$, a less intense hue and atypical flavors, spoiling wine's aromatic profile, which usually benefits of lower temperatures [9]. Hence, in the last few years several studies have focused on finding valuable solutions to mitigate these effects. From different canopy management techniques (e.g. winter late pruning, leaf removal, shoot thinning etc.) $[10,11]$ to the application of antitranspirant sprays [12, 13, 14], the efficiency of these adaptation strategies has been widely tested and this is still the main focus of a large number of studies.

So, studying the climate of a specific area and the effects of its changes on different environments acquires a key role in the definition of the most suitable adaptation strategies.

For this reason, the aim of this study is to evaluate climate evolution in a period of almost thirty years and the effect of this evolution on harvest data in an important viticultural area of central Italy.

\section{Materials and Methods}

The study has been carried out from a dataset made available by a cooperative winery (Cantine Belisario s.a.c.) located in Matelica, in the Marche region, central Italy (Fig. 1). The harvest dates of Verdicchio Bianco grapes (i.e. when delivered to winery) have been used to determine the first and the last day of harvesting period, the date in which half of the grapes were harvested, and grape sugar concentration. As for the climate characterization of the area, data from weather stations of Protezione Civile della Regione Marche located in the nearby area (available online) were used. These data were daily rainfall, daily maximum temperature (Tmax) and minimum temperature (Tmin) from 1989 to 2016.

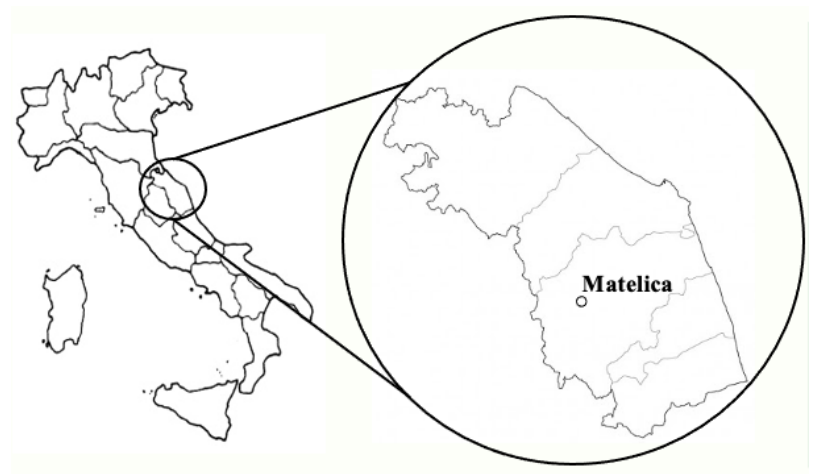

Fig. 1. Position of Matelica area in Italy.

\subsection{Bioclimatic indices}

The first step carried out was the characterization of the climate of the area in the period 1989-2016. The meteorological data were used to calculate daily mean temperature $($ Tmean $=(\operatorname{Tmax}+\mathrm{Tmin}) / 2)$ daily temperature ranges $(\Delta \mathrm{T})$ as the difference between daily maximum and minimum temperatures and total rainfall per year. Heat summation to which vines were exposed has been calculated as the sum of growing degree-days (obtained by subtracting the thermal threshold of $10^{\circ} \mathrm{C}$ from the mean daily temperature) in different periods of the year (Amerine and Winkler index, IAW).

\subsection{Statistical analysis}

The statistical method of a simple linear regression was used to analyze the climatic trend of the area, the trend of harvest date and to study their relationship.

\section{Results and Discussion}

\subsection{Climatic characterization}

Climatological data of Matelica area are shown in table 1. The yearly mean temperature of Matelica area stood at $13,3{ }^{\circ} \mathrm{C}$ during $1989-2016$ period. Looking at the mean temperature values for the three periods of analysis reported in table 1 (1989-1998, 1999-2008, 2009-2016), the trend of an increase of about $0,20^{\circ} \mathrm{C} /$ decade registered in the 1950-2000 period [2] was not confirmed in recent years. Hence, it is possible that climate change effects had been more consistent in the 80 s and now we are facing a stationary phase in the area, where thermal increments are somewhat milder.

Similarly, heat summation from April to October (Amerine \&Winkler index) did not show an increasing trend in the period of analysis, with the highest value of 1814 units registered for the decade 1999-2008 and with a mean value of 1748 units for the entire period 19892016. However, we must underline that this last thermal summation data exceeds the value recorded in the fifty years $1950-2000$ by about 200 units.

Daily temperature range values increased progressively from 1989 to 2016 , starting from $10.4{ }^{\circ} \mathrm{C}$ in the first decade and reaching $10.8^{\circ} \mathrm{C}$ in the $2009-2016$ period. In the whole period mean value was of $10.6{ }^{\circ} \mathrm{C}$, which is quite constant: this parameter is relevant in the characterization of the microclimate of the area.

In the 28 years of analysis average annual rainfall was of $899 \mathrm{~mm}$, a value similar to that of the fifty years 1950-2000. However, it is possible to identify an increasing trend of average annual rainfall, which passed from $839 \mathrm{~mm}$ during the period 1989-1998 to $1026 \mathrm{~mm}$ in the years between 2009 and 2016.

\subsection{Harvest data analysis}

In the 1989-2016 period a general anticipation of the harvest has occurred, as shown in table 2 . The beginning of harvest date showed the most relevant anticipation, moving from the beginning of October (DOY 278) for the period 1989-1998 to the early September (DOY 254) in the 2009-2016 period. This advance is partly due to the growing importance of the production of sparkling wines in the area and the consequent need to harvest grapes that are less sugary, but richer in malic acid than in an earlier stage of maturation. The end of harvest showed a minor anticipation of just 9 days from the first decade to the 2009-2016 period. Similarly, average harvest date, in which $50 \%$ of all grapes have been 
harvested, moved earlier of about a week in the analysed period.

Having this anticipation affected mostly the harvest beginning date with lower incidence on the end of the harvest, the duration of the whole harvesting period increase progressively throughout the years (tab. 2). As a matter of fact, if in the first ten years arvest lasted about one month (27 days on average), in the 2009-2016 period it required two more weeks (42 days).

Table 1. Yearly average values of mean temperature (T mean), Amerine \& Winkler index (IAW), daily temperature range $(\Delta \mathrm{T})$ and total rainfall registered in the Matelica area.

\begin{tabular}{|c|c|c|c|c|}
\hline Period & $\begin{array}{c}\mathrm{T} \text { mean } \\
\left({ }^{\circ} \mathrm{C}\right)\end{array}$ & IAW & $\Delta \mathrm{T}\left({ }^{\circ} \mathrm{C}\right)$ & $\begin{array}{c}\text { Total } \\
\text { rainfall } \\
(\mathrm{mm} / \text { year })\end{array}$ \\
\hline $\begin{array}{c}1950- \\
2000\end{array}$ & 12.6 & 1550 & $\begin{array}{c}\text { Not } \\
\text { available }\end{array}$ & 932 \\
\hline $\begin{array}{c}1989- \\
1998\end{array}$ & 13.3 & 1717 & 10.4 & 839 \\
\hline $\begin{array}{c}1999- \\
2008\end{array}$ & 13.4 & 1814 & 10.5 & 859 \\
\hline $\begin{array}{c}2009- \\
2016\end{array}$ & 13.1 & 1703 & 10.8 & 1026 \\
\hline $\begin{array}{c}1989- \\
2016\end{array}$ & 13.3 & 1748 & 10.6 & 899 \\
\hline
\end{tabular}

Table 2. Evolution of the beginning harvest date (bhd), average harvest date (ahd), ending harvest date (ehd) and harvest length of Verdicchio grapevines in the Matelica area in the 1989-2016 period.

\begin{tabular}{|c|c|c|c|c|}
\hline Period & $\begin{array}{c}\text { bhd } \\
(\text { DOY })\end{array}$ & $\begin{array}{c}\text { ahd } \\
(\mathrm{DOY})\end{array}$ & $\begin{array}{c}\text { ehd } \\
(\mathrm{DOY})\end{array}$ & $\begin{array}{c}\text { Harvest } \\
\text { length } \\
\left(\mathrm{n}^{\circ} \text { days }\right)\end{array}$ \\
\hline $\begin{array}{c}1989- \\
1998\end{array}$ & 278 & 289 & 305 & 27 \\
\hline $\begin{array}{c}1999- \\
2008\end{array}$ & 268 & 282 & 299 & 31 \\
\hline $\begin{array}{c}2009- \\
2016\end{array}$ & 254 & 282 & 296 & 42 \\
\hline $\begin{array}{c}1989- \\
2016\end{array}$ & 268 & 285 & 300 & 33 \\
\hline
\end{tabular}

The average harvest date showed a quite strong correlation with the heat summation from March to June, as indicated by the $\mathrm{R}^{2}$ value of 0.4628 (Fig. 2). These results are somewhat similar to what has been found by Di Lena et al. in Abruzzo region, where heat summation during this period proved to cause an anticipation of the beginning of harvest [3]. In our case thermal availability (IAW) of this period appears to have more influence on average harvest date, anticipating it of 7 days for each increment of 100 units IAW specifically.

Sugar accumulation of Montepulciano grapevines showed to be influenced by thermal availability IAW from July to September, as shown in a study carried out in Abruzzo region [4]. On the contrary, our results suggest that the ripening process of Verdicchio grapes in
Matelica is strongly influenced by heat accumulation from June to August (Fig. 3). In particular, increments of 100 units are associated to a rise of must sugar concentration of $0.66^{\circ} \mathrm{Babo}$. This difference found in other studies may be related to the different environment of the area: indeed, being characterized by lower temperatures, the whole summer period seems to play a crucial role in the ripening process.

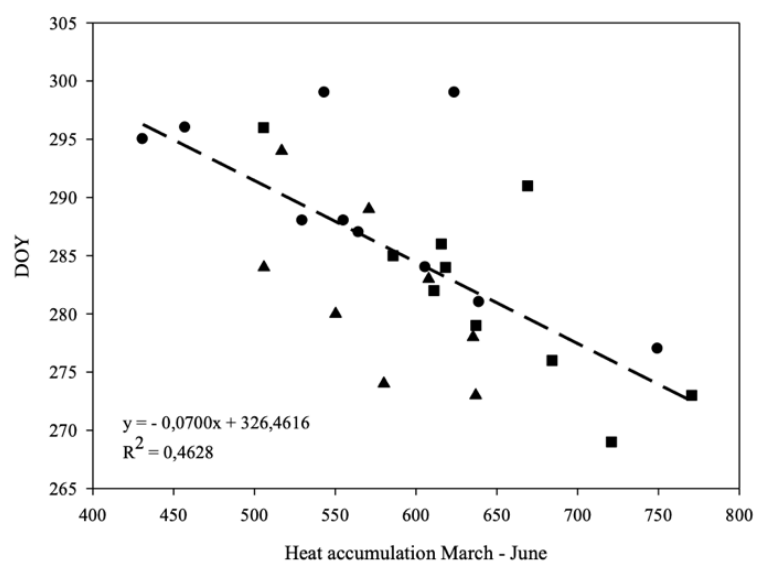

Fig. 2. Relation between heat summation from March to June and average harvest date in the period 1989-1998 (•), 19992008 (匹) and 2009-2016 ( $\mathbf{\Delta})$.

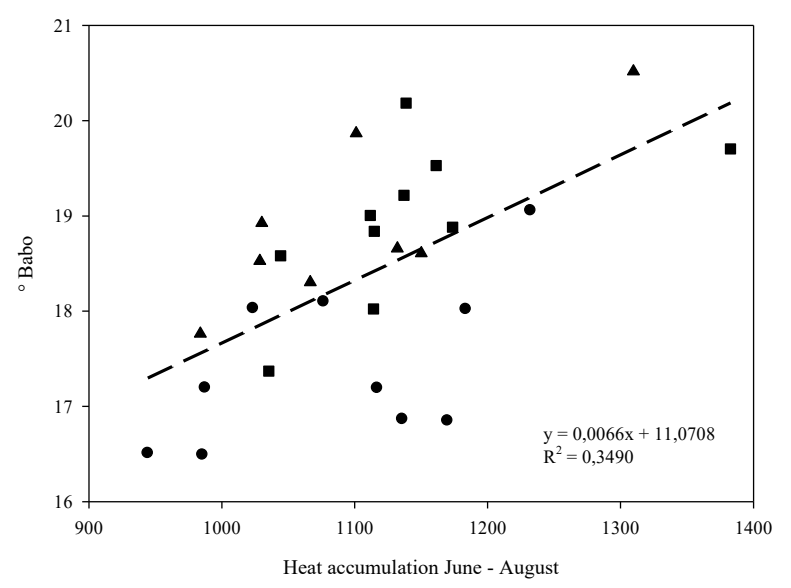

Fig. 3. Relation between heat summation from June to August and must sugar concentration ( ${ }^{\circ} \mathrm{Babo}$ ) in the period 1989-1998 $(\bullet), 1999-2008$ (•) and 2009-2016 ( $\mathbf{\Delta})$.

\section{Conclusions}

In the 1989-2016 time series, the climate of the area was characterized by average temperature values slightly higher than 1950-2000 period. Daily temperature ranges increased throughout the 28 years of analysis, enhancing this distinctive aspect of the climate of the area. Data concerning total annual rainfall suggest that this area was less affected by the decrease of precipitation usually associated with climate change in Mediterranean areas, actually a slight increase was observed.

Similar to what has been showed for different environments with other cultivars, even Verdicchio grape harvest in Matelica area has experienced a general 
anticipation, mostly concerning the beginning of harvest, which advanced of about one month. This is linked to the higher thermic regime, especially during the early stages of vine development, and innovation and modernization of vineyards (i.e., selected clones, higher planting densities and new cultivation techniques) which took place starting from 1990s.

Verdicchio grape harvest date appears to be influenced by the heat summation from March to June, in accordance with what has been found in previous studies [3]. In particular, the average harvest date shows a quite strong relationship with thermal availability during this period.

Summer thermal availability (from June to August) has an effect on berry sugar accumulation. In this case, our results are different from other studies [4], where sugar concentration appears to be influenced by heat accumulation from July to September. This difference can be valid for the area of study and its environment: apparently, in the Matelica area, where temperatures are mild and usually never reach high values, active temperatures during summer appear crucial to guarantee the conclusion of berry ripening.

\section{References}

1. V. Masson-Delmotte, P. Zhai, H.-O. Pörtner, D. Roberts, J. Skea, P.R. Shukla, A. Pirani, W. Moufouma-Okia, C. Péan, R. Pidcock, S. Connors, J.B.R. Matthews, Y. Chen, X. Zhou, M.I. Gomis, E. Lonnoy, T. Maycock, M. Tignor, and T. Waterfield, Summary for Policymakers (IPCC 2018)

2. R. Spina, S. Stortini, R. Fusari, C. Scuterini, M. Di Marino, Caratterizzazione climatologica delle Marche: campo medio della temperatura per il periodo 1950-2000, http://www.regione.marche.it/RegioneUtile/Protezione-Civile/Progetti-ePubblicazioni/Studi-Meteo-Idro (2007)

3. B. Di Lena, O. Silvestroni, V. Lanari, A. Palliotti Theor. Appl. Climatol., 136 (3-4), (2019)

4. V. Lanari, A. Palliotti, P. Sabbatini, G. S. Howell, O. Silvestroni, Sci. Hortic., 179, 239-247 (2014)

5. G.V. Jones, E. Duchene, D. Tomasi, J. Yuste, O. Braslavka, H. Schultz, C. Martinez, S. Boso, F. Langellier, C. Perruchot, G. Guimbertau, XIV International GESCO Viticulture Congress, Geisenheim, Germania, 54-61 (2005)

6. D. Tomasi, G.V. Jones, M. Giust, L. Lovat, F. Gaiotti, Am J Enol Vitic, 62, 329-339 (2011)

7. F.M. De Toda, J.C. Sancha, P. Balda, SAJEV, 34(2), 246-251 (2013)

8. F.M. De Toda, P. Balda, Vitis, 53(4), 171-176 (2013)

9. A. Palliotti, S. Tombesi, O. Silvestroni, V. Lanari, M. Gatti, S. Poni, Sci. Hortic., 178, 43-54 (2014)

10. O. Silvestroni, V. Lanrai, T. Lattanzi, A. Palliotti, Aust. J. Grape Wine Res., 24, 478-486 (2018)
11. O. Silvestroni, V. Lanari, T. Lattanzi, A. Palliotti, J. Vanderweide, P. Sabbatini, Aust. J. Grape Wine Res., 25, 30-42 (2019)

12. L. Brillante, N. Belfiore, F. Gaiotti, L. Lovat, L. Sansone, S. Poni, D. Tomasi, PLoS ONE, 11 (2016)

13. O. Silvestroni, V. Lanari, T. Lattanzi, E. Dottori, A. Palliotti, Aust. J. Grape Wine Res., 26, 363-371 (2020)

14. A. Palliotti, S. Tombesi, O. Silvestroni, V. Lanari, M. Gatti, S. Poni, Sci. Hortic., 178, 43-54 (2014) 